\title{
Transdisciplinarity across two-tiers
}

\section{The case of applied linguistics and literary studies in U.S. foreign language departments}

\author{
Chantelle Warner \\ University of Arizona
}

In the ten years since the Modern Language Association published their report, "Foreign Languages and Higher Education: New Structures for a Changed World" (2007) dissatisfaction with the "two-tiered configuration" of US foreign language departments has become increasingly vocal. While the target of the criticism is often the curriculum, it has often been noted that programmatic bifurcations mirror institutional hierarchies, e.g. status differences between specialists in literary and cultural studies and experts in applied linguistics and language pedagogy (e.g. Maxim et al., 2013; Allen \& Maxim, 2012). This chapter looks at the two-tiered structure of collegiate modern language departments from the perspectives of the transdisciplinary shape-shifters who maneuver within them - scholars working between applied linguistics and literary studies. These individuals must negotiate the methodologies and the institutional positions available to them - in many instances, the latter is what has prompted them to work between fields in the first place. The particular context of US foreign language and literature departments serves as a case study of the lived experiences of doing transdisciplinary work in contexts that are characterized by disciplinary hierarchies and the chapter ends with a call for applied linguistics to consider not only the epistemic, but also the institutional and affective labor needed to sustain transdisciplinary work.

Keywords: applied linguistics, literary studies, transdisciplinarity, institutional power

\section{Introduction}

As Hawkins and Mori note in their introduction to a recent special issue of the journal Applied Linguistics, a series of what they dub "trans-perspectives" - transnational, transcultural, translocal, transpatial, transmodal, translanguaging, and 
translingualism - have become critical key terms in recent years and transdisciplinarity seems perfectly at home with them. Some prominent voices from within have even argued that applied linguistics has always already been a transdiscipline (Douglas Fir Group, 2016; Grabe, 2010; Halliday, 2001; Ortega, 2013; Pennycook, 2018; Perrin, 2012). ${ }^{1}$ If applied linguistics is by definition a transdiscipline, it seems easy to argue that current discussions around transdisciplinarity in applied linguistics are a case of much ado about nothing (see Pennycook, this volume). And yet, to declare applied linguistics transdisciplinary promotes what may without a doubt be a tenable intellectual position, while sidelining important considerations of whether and when it is also a tenurable position - with reference here to the prestige structures U.S. cultures of academia. In other words, how does transdisciplinarity impact the status of individuals whose academic lives are situated not only in the spaces of disciplinary imaginations, but also through "infrastructural conditions and legacies of discourse and institutional power that precede and condition [their] existence"' (Butler, 2016, p. 21; cited in Kramsch, 2018, p. 111)? This becomes all the more acute when the nexus of transdisciplinarity in question is not situated among the neighboring disciplines typically reflected in the conference programs and journal pages that constitute the shared discourse spaces of applied linguistics, but rather relates to an at times fraught relationship of institutional necessity and historical contention. Such is the shared context of applied linguistics (specifically, second language studies) and literary studies in U.S. collegiate foreign language departments.

Foreign language, literature and culture (henceforth abbreviated as FLLC) departments in U.S. postsecondary institutions are certainly not unique for bringing together scholars with different disciplinary orientations, but the stratified relationship between those disciplines and the extent and consistency with which that relationship has been reproduced in program structures, curricular design, and hiring patterns is certainly particular (Allen, 2009; MLA, 2007). For this reason, the stories of scholars whose work crosses applied linguistics and literary studies in these departments provide interesting case studies for the lived experience of doing transdisciplinarity work in contexts characterized by disciplinary hierarchies. This paper considers transdisciplinarity not first and foremost as an epistemological perspective - although the conclusion will zoom back out to potential implications for how applied linguistics as a collective intellectual enterprise conceives of its transdisciplinarity; instead, the focus in this article is on the self-reported acts of positioning and maneuvering that scholars

1. Ortega's (2013) article is perhaps the most critical of those listed, as part of her argument is that second language acquisition has not adequately lived up to its claims of transdisciplinary relevance. 
undertake to fit into the institutional positions available to them - positions that are on the one hand often ill-suited or even inhospitable to the kinds of transdisciplinary work these scholars wish to achieve in their teaching and research. The basis for my discussion of transdisciplinarity as a lived experience will be a series of interviews that I conducted with scholars at various career levels who work or have worked between applied linguistics and literary studies and moreover whose academic contributions are shaped by the intersections of these applied linguistics and literary studies, but I will also draw from my own experiences as a peer and participant in this collective. Despite the particularity of these individual experiences, I will argue in the final section that they can be taken as a case study with lessons for how applied linguistics might expand and promote transdisciplinary scholarship.

\section{Transdisciplinarity as a discourse within U.S. foreign language, literature, and culture departments}

Within the discourse communities of U.S. American second language studies, ${ }^{2}$ transdisciplinarity has received renewed attention in light of two widelydiscussed publications from the past little more than a decade: the 2007 Modern Language Association (MLA) report "Foreign Languages and Higher Education: New Structures for a Changed World" - and the Douglas Fir Group's, 2016 "A Transdisciplinary Framework for SLA in a Multilingual World" from the Modern

\section{Language Journal.}

The more recent of the two, from the Douglas Fir Group - a collective of 15 North America-based applied linguists - argues for a transdisciplinary approach to second language acquisition on two intersecting levels. First, the field of second language studies is beyond academic disciplines, in that it should inform and be informed by the real-world experiences of those who live and learn multiple languages (see also Brumfit, 1997, p. 27). At the same time, the Group argues, transdisciplinarity requires an approach that is "integrative" (2016, p. 19; see also Byrd Clark, 2016; Ortega, 2013, p. 7), drawing from a wide range of fields that span beyond a single discipline including linguistics, psychology, anthropology, cognitive science, education, and sociology (to cite those named by the Douglas

2. In this article, I will use the phrase second language studies, in order to reflect a broader field of research around this topic, which includes scholars who identify their work as second language acquisition, as second and foreign language pedagogy, or as fitting into other related fields such as educational linguistics or second language writing, all of which are typical areas of expertise for applied linguists in FLLC departments. 
Fir Group). The Group's manifesto locates the need for a more pronounced commitment to transdisciplinarity in the current historical moment characterized by transnationalism, multilingualism, globalization, and technologization (Douglas Fir Group, 2016, p. 19; see also Byrd Clark, 2016, p. 3).

The MLA Adhoc Committee on Foreign Languages was convened to examine the "real world" problems of contemporary language teaching in the U.S. and comprised a transdisciplinary group of seven scholars working in U.S. modern language departments, including experts in applied linguistics, foreign language education, cultural studies, and comparative literature. One of the main points of emphasis in the report is the programmatic bifurcations common to the foreign language humanities departments, which likewise reflect institutional hierarchies, e.g. status differences between specialists in literary and cultural studies, who tend to hold tenured positions and teach upper-level undergraduate and graduate courses, and experts in applied linguistics and language pedagogy, who are in many cases the sole scholar in that field in their department, are more likely to be in a contingent or non-researcher position, and are often responsible for the lowerlevel curricula (see Allen \& Paesani, 2010; Kramsch, 1993; Maxim et al., 2013).

While the MLA report has brought this conversation to the fore, discussions about disciplinary tensions in FLLC departments are more than two decades old. In a 1999 essay with the telling title "What is second language acquisition and what is it doing in this department?", Van Patten provided a sort of primer for FL departments to help them to understand the new disciplinary strangers among them. In this essay, he laid out some of the tensions that were plaguing and that in many ways still plague applied linguists situated in these institutional spaces, including differing disciplinary publication practices that were inadequately recognized in standards for promotion and tenure and a tendency for colleagues to conflate applied linguistics with teaching methodology (Van Patten, 1999; see also Kramsch, 2015, p. 455).

Writing only a few years earlier but from the perspective of a literary and cultural studies scholar, Berman (1994) examined the institutional forced marriage of linguistics and literature in foreign language departments on disciplinary grounds, arguing that we should ask ourselves "why we think language, literature, and culture ought to be taught at all and whether they belong together for other than merely conventional reasons" (Berman, 1994). Berman's essay goes on to advocate for a form of cultural studies that has dominated the foreign language humanities since the 1980s or 1990s and which is arguably a-lingual in that the emphasis is on intellectual and thematic trends not on the language(s) that mediates them. The movement towards "methodological monolingualism" (Gramling, 2016, p. 529) has conceptual underpinnings that are anchored in theoretical paradigms from sociology and anthropology, but it is also importantly pragmatically-driven. 
Publishing and teaching in English held the promise of a wider reach - even to students (and colleagues) who do not have time to learn new languages.

Following a parallel trajectory, the position of applied linguistics within the North American academy has grown stronger during these same decades and this has pushed back on the structures of FLLC departments in some of the ways Van Patten had predicted. This is seen, for example, in the evolution of the position of Language Program Director (LPD) - a position, which in the past had been treated as a service responsibility that could be taken on by a faculty member of any specialization. Over the course of the 1990s and 2000s, it became more common to treat this as a research position and thus to hire someone with a specialization in applied linguistics or second language pedagogy. At the same time, working as LPD has a clear impact on the scholarly work those in these positions pursue. In a survey of LPDs in FLLC departments conducted by Stacy Katz and Johanna Watzinger-Tharp several years ago (Katz \& Watzinger-Tharp, 2005), the majority of respondents (79.1\%) reported being engaged actively in research related to foreign language pedagogy - although many had conducted doctoral research in another field; 10 of the 45 described the field of their doctoral thesis as applied linguistics - and only $31 \%$ of the respondents were in non-tenure track positions. This means that a greater percentage of scholars in the humanities who graduated in the last decade will have worked at some point in their studies with an active researcher who has some background in applied linguists; however, it is particularly important to note within the context of this volume, that most of the scholars surveyed by Katz and Watzinger-Tharp positioned themselves between multiple disciplines and none of them characterized their research as falling exclusively within applied linguistics (see Katz \& Watzinger-Tharp, 2005).

Because they are underrepresented in the departments in which they work, applied linguists working within the institutional cultures of U.S. FL fields often experience transdisciplinarity in an additional sense, which is not captured in the Douglas Fir Group's discussion with its focus on the intellectual desiderata of field rather than the career paths of the individual researchers who inhabit it. Byrd Clark describes the ways in which an individual's repertoire can be shaped through transdisciplinarity quite compellingly in a brief sketch of her own biography:

For example, I have a background in literary criticism, French, and comparative literature, as well as applied linguistics (particularly sociolinguistics), and I teach graduate courses in second language education and multilingualism. I have also been a public K-12 schoolteacher of French, Spanish, and English as a Second Language (ESL) in different international contexts. An often-unrecognizable facet of transdisciplinarity is that I am also familiar with the didactique des langues in French, which differs from the translated equivalent of "teaching languages" 
in English. In my work, I further cross between different linguistic varieties of French, English, and Italian.

(Byrd Clark, 2016, p. 8)

At the B.A. level in U.S. higher education, applied linguistics scarcely exists and even at the M.A. and to some extent Ph.D. levels programs are often dominated by TESOL, that is the teaching of English to speakers of other languages. ${ }^{3}$ For this reason, scholars whose academic homes are in spaces devoted to languages other than English are perhaps more likely to have a career that has been shaped by movement between different academic disciplines and their counterparts in other regions of the world, and which often includes at least an undergraduate if not an M.A. degree, in an area studies program that privileges literary scholarship, because often these scholars discovered applied linguistics and second language studies accidentally while attaining a degree dominated by another field. As suggested by the data from Katz and Watzinger-Tharp's survey, the close association between applied linguistics researchers and the administrative position of the LPD in FLLC departments serves as a further impetus for disciplinary crossings beyond the doctoral degree.

The institutional landscape described here suggests that fertile ground has been laid over the past couple of decades for transdisciplinary work between applied linguistics and literary studies. And indeed, many scholars working in these fields have argued that languages, literatures, and cultures are not such strange bedfellows after all. In a relatively early contribution to this conversation, Janet Swaffar (1999) argued that "foreign languages" is a discipline in its own right.

...foreign language study is a discipline with four subfields (language, literature, linguistics, and culture) that asks the question, How do individuals and groups use words and other sign systems in context to intend, negotiate, and create meanings?

Characterizing "foreign languages" as a discipline may feel no less problematic than applied linguistics, but Swaffar's suggestion can rightly be read as an attempt to create a sense of common ground for a typified set of institutional relations and the general sentiment that colleagues in foreign language departments can and ought to embrace a shared frame of reference for their work has been voiced by many others.

The idea that meaning-making might provide a central shared concern for scholars from diverse disciplines working in foreign languages, which Swaffar espouses here, has found much traction among U.S.-based applied linguists

3. This observation is based on the most recent (2015) survey of U.S. programs for applied linguistics compiled by the Center for Applied Linguistics. See http://www.cal.org/what-we-do/ projects/survey-of-applied-linguistics-programs 
working in foreign language teaching and learning over the past two decades (e.g. Hiram \& Maxim, 2004; Kramsch, Howell, Warner, \& Wellmon, 2007; Maxim et al., 2013; Swaffar et al., 1991; van Lier, 2004; Warner, 2011). In part prompted by the 2007 Modern Language Report, a growing body of applied linguists within FLLC departments have approached this as not only an intellectual but also a curricular problem, by trying to reimagine the desired learning outcomes of collegiate foreign language programs in terms of literacy and design awareness (Kern, 2000; Paesani et al., 2016), textual thinking (Maxim, 2006), symbolic competence (Kramsch, 2011), semiotic agility (Warner \& Gramling, 2013, 2014) and literary thinking (Richardson, 2017).

It is noteworthy that the theoretical and thematic emphases advocated by these scholars depart somewhat from the SLA described by Van Patten as foreign to foreign letters and humanities and return quite deliberately to the philological roots from which FLLC - and the disciplines in the humanities and language sciences housed within them - first grew. Transdisciplinary work of this sort that draws from traditions common to the multiple disciplinary traditions present in a department seems a productive step towards dismantling the institutional bifurcations problematized within the MLA report and elsewhere; however, even with the best of intellectual intentions, old systems can be difficult to overcome.

One aspect that has remained relatively intact is the balance of power between applied linguists and literary studies scholars in many departments. In a response immediately following the publication of the MLA report Elizabeth Bernhardt expressed concern that the Report inadvertently reified the same two-tiered system that it set out to critique by calling on literature faculty to have a hand in "teaching language courses and in shaping and overseeing the content and teaching approaches used throughout the curriculum, from the first year forward" (MLA, 2007, p. 7), without providing recommendations for the converse, i.e. that applied linguists might apply their expertise in shaping the upper-level curriculum (Bernhardt, 2010, p. 2). Based on the research publications and reports that have appeared in the past a little more than a decade, in which the MLA is cited as a discursive guiding light, it seems that in actuality the language teaching specialists have overwhelmingly taken on the work of addressing curricular bifurcation, in part by drawing upon intellectual resources from within applied linguistics, especially those that frame language learning as the development of meaning making, in part by drawing from adjacent disciplines, in particular educational research, and in part by drawing on their own hybrid biographies, which - as exemplified by Julie Byrd Clark - often include substantial training in literary studies (see also Bernhardt, 2010, p. 2).

At the same time, the MLA report seems to suggest missed opportunities for transdisciplinarity within FLLC departments, which have arisen because of these 
hierarchical divides and stratifications that are not necessarily unidirectional. Here it is interesting to note the set of disciplines recognized by the Douglas Fir Group in their vision of transdisciplinary second language acquisition research. With the possible exception of education and research areas that cross into the natural sciences (e.g. psychology, neurolinguistics), they all fit fairly squarely in standard categorizations of the social sciences. The arts and humanities are almost completely missing from the picture, although particular forms of artistic expression appear among other forms of "popular media" (Douglas Fir Group, 2016). In the case of scholars working in U.S. FLLC departments at least, there is thus a potential tension between intellectual valorizations of transdisciplinarity in applied linguistics and the forms of meaning they mediate between in their teaching and research practices.

In the section that follows, I turn to the stories of these disciplinary gobetweens in order to consider how the politics of the everyday can have both positive and negative consequences for the scholars who move across and beyond disciplinary bounds, especially in contexts where those dividing lines mark longlived struggles for legitimation. Two interconnected research questions guide this study: How do scholars in FLLC departments whose work crosses the lines between applied linguistics and literary studies describe the intellectual motivations and affordances of transdisciplinary inquiry? How do these same scholars describe the institutional effects of transdisciplinary scholarship? My intention is to bring the subjective dimensions of transdisciplinary applied linguistics to the fore, but of course the personal is always political. Based on an analysis of the interview testimonies and informed by my own experiences - both of which are the focus of the following sections -, I will argue in the conclusion that the experiences of scholars who practice transdisciplinarity within FLLC fields and the ways in which these experiences have shaped the directions of their scholarly work and their paths of career advancement have direct implications for applied linguistics as a field of research and its own potential (trans)disciplinary blind spots.

\section{Stories from across two tiers}

In order understand the subjective experiences of scholars who work transdisciplinarily between applied linguistics and literary studies, I conducted semistructured interviews with 10 colleagues in the field, whom I know professionally and, in most cases, also personally. The 11th story - which is presented first in the data - is an autobiographical reflection on my own experiences.

Because the interviewees were my colleagues, my role in the interviews was most similar to that of a participant observer, in that rapport was pre-established 
and there was an assumed sense of reciprocity. The interviews ranged between around half an hour and an hour in length and were loosely structured around seven questions (see Appendix A), although conversation was allowed to flow organically as new topics of interest emerged, the questions were designed to elicit the participants' perceptions about their work, how they feel they have been perceived by others, and their experiences as scholars who are positioned both within local departmental contexts and larger scholarly cultures. Interviews were then analyzed thematically, first with reference to notes that had been taken during the interviews and then by reviewing the interview recordings for additional themes that may have been overlooked. In the discussion below, I will focus on only four of the themes, which were selected on the basis of their representational qualities, i.e. prominence and salience across the interviews, and their relevance to the question that guides this article, namely what is the lived experience of transdisciplinary scholarship in contexts of disciplinary hierarchy?

Although it is impossible to claim comprehensiveness in a study such as this, I attempted to recruit participants who represented different career levels, institutional roles, and research interests. At the time of their interview, two held the position of Lecturer and were early in their careers and one was retired but spent her career as a Lecturer. In comparison to the use of the term in other academic cultures, in U.S. higher education, the title Lecturer typically designates that the person is not eligible for tenure. Lecturers are also importantly not considered research faculty; their workload instead consists primarily or exclusively of teaching and service responsibilities. Jeanne, who was the only of the participants who does not hold a Ph.D., served as a Lecturer in an institution where all language teaching faculty are lecturers and professorial positions in FLLC departments are reserved for scholars in literary studies. Both Louise and Iris had recently completed their Ph.Ds. and their experiences represent a more recent trend in the field, the conversion of an increasing number of positions within FLLC departments from Tenuretrack Professor to Lecturer or to non-tenure-eligible professional positions (e.g. Professor of the Practice). Two of the interviewees were Assistant Professors at the time of the interviews, Aaron and Olivia, but both have since been promoted to Associate Professor. Together with Paul, who was a recently promoted Associate Professor when we spoke, they represent faculty in the middle of their careers. I might be considered the fourth representative of this constituency, as I was promoted to Associate Professor within a couple of years of all of them. Anne, Chris, and Emma were all Associate Professors as well, but they have held this position for longer that the previously mentioned individuals. Finally, Alice was the single Full Professor I interviewed.

The individuals whom I interviewed all work or have worked in French and German departments. This is no doubt a bias in my own professional connections, 
but also perhaps indicative of larger trends and histories. Spanish departments are often large enough to devote a research position exclusively to an applied linguist or even multiple applied linguists, while some of the until recently less commonly taught languages like Arabic and Korean were born out of a later boom in language study separate from any philological tradition. Thus, although the issues of disciplinary hierarchy may be shared, French and German Departments have been more likely to seek out scholars who can teach courses in both literature and culture, while also satisfying administrative and curricular needs for a specialist in language teaching and learning and that applied linguists residing in these departments are much more likely to have had a background in literary studies themselves. ${ }^{4}$

A brief overview of the interview participants can be found in Appendix B of this article. Both here and throughout the presentation of the interviews I have used pseudonyms and kept personal details to a minimum. In some cases, I have also intentionally left it ambiguous which participant said what. Because the majority of the interviewees are currently located in the same institutional contexts, which they described and sometimes critically, and because applied linguists in the foreign language fields, let alone in German and French specifically, constitute a relatively small body of scholars, there was a need to protect identities of the participants, even as I have tried to share enough for the reader to understand the context of their particular experiences.

\section{a. My story}

I completed my graduate studies in a German Studies Program, whose faculty included literary and cultural studies scholars, German linguists, and a single applied linguist - who in this case was not the LPD, as this position was not a tenure-track faculty job at this institution. The experience of shunting between seminars in literary studies and applied linguistics shaped my research interests in multilingualism, second language literacy, and literary stylistics. I finished my Ph.D. in 2007 and at that time the academic job market for German seemed to be heeding, at least somewhat, the recommendations of the MLA report that had been released that year. I applied to and interviewed for both positions for which the desired candidate was explicitly described as an applied linguist and for more generalist positions where expertise in literary studies was a must.

My first academic position, which I have held since then, was in a German Studies Department, where I was hired with the contractually-expressed

4. Evidence of these difference between language departments can be found in the most recent "Job Information List" published by the Modern Language Association, available at https:// www.mla.org/content/download/77249/2164846. 
expectation that I would take on the role of the LPD from the current director (a tenured faculty member). I had the fortune of being able to ease into that position - by working first for five years as the curriculum coordinator of the thirdyear courses and only after being award tenure being asked to take over the more work-intensive task of directing the first and second years. My home department has degree programs at the B.A., M.A., and Ph.D. levels and the post-graduate degrees both include tracks allowing students to specialize in literature, culture, and pedagogy (at the M.A. level) and applied linguistics/second language studies (at the Ph.D. level). I am also affiliated with an interdisciplinary doctoral program in Second Language Acquisition and Teaching on my campus. Over the course of the past almost 10 years, since I started in my position, I have had the opportunity to teach undergraduate and graduate courses in both applied linguistics and literary studies and many, which include elements of both. I was able to attain tenure in my department, even with what might be perceived as a somewhat eclectic set of research interests.

When cast against the backdrop depicted in the previous section and data from the most recent MLA job lists, it is clear that my situation has been relatively privileged. I was able to find a tenure-track position straight out of graduate school and I stepped into that position just a couple of months before the 2008 recession. In the years that followed, many universities enforced hiring freezes and even after these were lifted, the financial crisis left a culture of austerity in American high education, which has reduced the number of tenure-track positions in all areas. Given the ambiguous nature of the LPD position - part administrator, part teacher, part scholar - these seem to often be the first to be converted to nontenure-eligible (i.e. non-research) positions within FLLC departments.

At the same time, I have experienced firsthand the power hierarchies between the fields within which I work and the disciplines from which I draw. As I was completing my Ph.D., one of my professors expressed incredulity that I was applying for tenure-track positions with the work that I do, i.e. work that integrates applied linguistics. When I arrived to campus to begin in a position, for which I understood I was chosen exactly because my work moves between literary studies and applied linguistics, I was asked to identify myself as either one or the other for the purpose of tenure and promotion. The fact that my department offers tenure and promotion criteria, which distinguish between different scholarly profiles was a sign of strong historical presence of applied linguists in that program, ${ }^{5}$ but at the same time, the solution of having two sets of distinct criteria is a materialization

5. The American Association of Applied Linguistics maintains and regularly updates a set of tenure and promotion guidelines for applied linguists, which members can use to help educate departments without this kind of precedent. See http://www.aaal.org/?page=PT 
of the reality that, as Russell (2005) argues, the fluid nature of transdisciplinarity is an anathema to institutionalization. I selected the applied linguistics track not only because I self-identified as an applied linguist who works with literary language, but also because it seemed to be the more flexible of the two. In my first two years as an assistant professor, I was then given conflicting advice from my senior colleagues as to whether the publication of a monograph - the golden ticket to tenure in most literary studies departments - would be valued, if I was going up for tenure as an applied linguist. ${ }^{6}$ This too is an ironic twist given the years of advocacy by applied linguists in FLLC departments, who have worked to convince their colleagues that theirs is an "article field" rather than a "book field." There are also the subtler sorts of effects, for example, my profile makes it easy for colleagues to position me as a linguistics person or a literature person, depending on which suits a particular purpose or argument, which has had both advantages (in terms of the range of opportunities presented to me) and disadvantages (especially in terms of workloads).

\section{b. The interviews}

In the sections that follow, I turn to the interview data. Each section focuses on a particular theme related to the scholars' motivations for pursuing transdisciplinary work and their experiences with institutional politics and perceptions of legitimation that was salient in most or all of the interviews. At the end of each of these sections, I will draw out some broader implications for discussions of (the) transdisciplinarity of/in applied linguistics.

\subsubsection{Transdisciplinary motivations}

As already noted, applied linguistics is rarely introduced to students at the B.A. level and even at the M.A. and in some cases Ph.D. levels of FLLC programs, students specialize in a particular track but are expected to take seminars in a range of disciplines proportionate to those the faculty in their departments represent. Alice - the most senior of the interviewees - spoke of this trend as she retold the history of her department and the configurations of people and ideas that led to a "fiat to redo the graduate program" so that students would get an exposure to multiple disciplines housed within German Studies early in their studies.

Thus, many of the interviewees discovered applied linguistics on the path through other disciplines, most often foreign language literature fields or the teaching of foreign languages. In many of the stories, there was a moment, a professional problem or an individual encounter (for example in a course offered during their

6. The eventual answer was yes. 
graduate studies), that shifted the person's scholarly work trajectory towards work that went beyond the disciplinary boundaries they knew. Many of the scholars used affectively-laden words such as "lucky," "relieved," "excited," "or "epiphany" as they described this moment. In seven of the interviews, the participant described a sense of being intellectually or professionally adrift in their programs of study or their academic lives which found at least momentary resolution in the discovery of more transdisciplinary approaches that pushed them beyond what they had experienced in their courses devoted to literary studies. In most, but not all, cases, transdisciplinarity involved the potential to move beyond what they had experienced as the disciplinary limits of another field.

The notion of transdisciplinarity as research that moves beyond disciplines to address the complex problems in the lifeworld was mentioned in all of the interviews as a motivation for their scholarly work. For all of the scholars interviewed, it was the relationship to the real-life situation of learning and using multiple languages that drew them to applied linguistics and for many of them, the lifeworld that most concerned them related to their students. The most frequently cited problem, which transdisciplinary work might help address, was in fact the bifurcated curriculum.

Jeanne, who was hired to serve as a language teacher and curriculum coordinator, described how her frustration with foreign language curricula that overemphasized literal meaning in the beginning levels had led her consider the potential role of poetics in language teaching and learning; however, this had put her at odds with some of her colleagues, especially the professorial faculty who specialized in literary studies. "My objectives did not fit established curricular design, and innovations that I hoped to share were politely ignored or ill received." Alice, Olivia, Anne, Emma, Iris, Louise, Chris and Paul also mentioned frustrations related to the teaching of languages and cultures or to how curricula were conceived, which had pushed them to embrace conceptual models that bridged and extended beyond applied linguistics and literary studies. Olivia, whose original motivation to pursue an M.A. degree in German literature was pragmatic - she was advised that she needed a background in literary studies to be successful on the job market as an LPD - described how the connections between literature and applied linguistics became meaningful through a curriculum development project she had the opportunity to work on during her Ph.D.In her worlds, "Genre and narrative were powerful terms that were uniting us."

In spite of the prominence of pedagogical concerns, many of the scholars also mentioned intellectual motivations besides language teaching. Although Chris, who served for many years as LPD and now was serving as a language center director, had built a career of work related to language teaching and learning, his initial moment of epiphany came while reading poems in an M.A. seminar on 
French literature and seeing the clarity of the analysis that a careful attention to linguistic detail afforded. This then motivated his move into applied linguistics, but also his continued interested in poetics and language use. Aaron described his primary motivation as the pursuit of complex projects related to multilingualism and identity, which pushed him to be a "border skirmisher," combining applied linguistics methods with approaches from cultural studies and critical theory.

The presence of an individual faculty mentor who had introduced them to applied linguistics research was a recurring theme in most of the interviews. As already indicated, there has recently been a reverse in the trend across the 1990s and early 2000s, which lead more FLLC departments to include at least one research faculty working in applied linguistics. There does not seem to be an indication that these hiring patterns echo enrollment-trends or student needs. In other words, there does not appear to be an increased demand for literature courses and a decreased interest in language study. Instead, the decision to devote tenure lines to literary studies most often stems from tradition (e.g., traditional departmental configurations, which include specialists representing different epochs). The effect is that the potential for the kinds of encounters and happenstance stumbles from literary studies into applied linguistics that Byrd Clark and my interview participants described might become more infrequent. This resulting decrease in the number of applied linguists in FLLC departments not only has implications for the shape of these programs, but also for applied linguistics in the U.S., because there are so few positions outside FLLC departments for applied linguists who work on languages other than English.

\subsubsection{Institutional politics of belonging}

Olivia, who had begun her graduate studies during the 1990s, recounted in her interview how she had been advised that she would need to have a Ph.D. in either German philology or literary studies to be considered for an academic position. This points to a particular aspect of the professional lives of applied linguists in foreign language studies that might seem quite odd to academics in other departmental and disciplinary contexts. In order to be successful as applied linguists, these scholars need a solid training in this field, but in order to gain access to the kinds of positions available to them (namely as LPD in an FLLC department), they are also often expected to have a background in a different discipline with its own traditions and forms of knowledge. In response to my question about how she viewed transdisciplinarity in relation to her own work, Olivia commented, "I have not seen the term transdisciplinary used in the context of LPDs, but obviously a lot of LPDs see themselves as straddling multiple worlds."

The pressure to be accepted as both in the fields of study one claims and in disciplines outside of one's primary area of specialization came up in various ways 
in almost all of the interviews. Anne, who had one of the most traditional linguistics backgrounds, described how she had spent years in a faculty position in which her expertise in second and foreign language pedagogy was palpably unwelcome when it came to discussions of the advanced language-literature courses in the program, ${ }^{7}$ but now as a center director at another institution she was able to leverage her ability "to speak their language" when she attended faculty meetings of the various language departments.

Iris, whose doctoral work had incorporated both applied linguistics and literary studies, responded affirmatively when I asked her if she felt that her transdisciplinary interests had helped her to attain her current position as a Lecturer in German, but also lamented that she had not been allowed to teach courses across the curriculum in her program, which only offers a Bachelor's degree. "What I expected when I took the position was that I would teach the full progression. Now due to certain structural issues...I have a feeling that I am going to end up still teaching the lower level classes." When I asked her to clarify what she meant by "structural issues," she explained that people with Ph.D. specializations in literature were being asked to teach the upper-level courses. "I feel like I am just the 'pedagogy person.' I think they see me as qualified for the culture class...but I feel like I also have to get some publications out there that show that I am also qualified to teach the literary classes." Iris' comment here echoes the earlier sentiments by Van Patten that applied linguistics is often reduced to pedagogy, which in turn is only associated with the lower levels of language instruction. She also noted that the inverse did not hold; that is, there was not an expectation that someone with a background in literary studies did not possess the requisite knowledge and understanding of language development to teach the "language classes" at the beginning of the curriculum. For Iris, whose research focused on the role of literariness in language teaching and learning, teaching assignments had a direct impact on her scholarly work She noted, "In my new position it has been difficult to work on things I had been working on as a graduate student."

It was not exclusively those specializing in applied linguistics who sometimes felt at odds with their position or perceived field. Emma - an Associate Professor specializing in German literary studies at a small liberal arts university, who has developed a very extensive professional profile as a developer of literacy-based materials for foreign language teaching - described how her previous experiences as a Language Program Director had made her a desirable hire for her current department, but that this same expertise had made her suspect to her colleagues,

7. Within FLLC departments courses such as these are taught in the second language and can thus be understood as content-based language courses, although they are not always designed with language development in mind. 
who were all literary studies scholars. "It was like an outsider invasion," she told me describing her first years in the department. It was her specialization in literary studies that allowed her to mitigate the "invasion" of second language studies that she instigated in her new department. She also expressed feeling as if the scholarly value of her more applied linguistic activities was not recognized by her colleagues.

Louise described her position as "walking on egg shells." She had been hired into her current position as a non-tenure track Lecturer because of her background in applied linguistics and second language studies. Despite her background in literary studies - she had completed her first M.A. in France in French literature and later completed a second M.A. in second language pedagogy and applied linguistics, she had not been asked to teach literary studies. She was however asked to teach linguistics courses that were a required part of the undergraduate program, for example courses in phonetics, and was finding ways to bring her interest in media studies and performance into this course in order to subvert the boundaries of language and literature within her own classroom.

The terms used by the participants to describe themselves are also revealing in terms of the politics of recognition that have shaped their academic identities. Only half of interviewees seemed completely comfortable identifying themselves as applied linguists, whereas the others might best be described as "practicing applied linguists," to borrow a term used by Katz and Watzinger-Tharp to identify individuals whose research and intellectual expertise is in a different area but who actively engage in the work of applying linguistics and language theories to real-world problems (Katz \& Watzinger-Tharp, 2016, p. 490). Only three of the ten identified as literary studies scholars, although a couple of the others offered creative work-arounds to allow them to emphasize the role of the literary in their work, such as "applied linguist with literary tendencies" (Chris) or "applied linguist who works with the art of literacy" (Jeanne).

Even those who did identify as applied linguists sometimes offered caveats. Paul told me that whether or not he labelled himself an applied linguist was a strategic choice, "it depends on who I talk to and in what context..." Paul and two of the others with whom I spoke expressed a preference for using what Paul called "non-labels" (e.g. reading researcher, second language studies) that describe areas of inquiry and thus enable them to more deftly maneuver across disciplinary boundaries and expectations in conversations with colleagues and in acts of professional self-presentation. Paul also talked about being in-between cohorts in graduate school because he "played both sides." He was neither accepted by the literary studies scholars, nor the applied linguists. Despite his success in the field including recognition for his contributions to applied linguistics, Aaron described sometimes feeling "tested" during Q\&A sessions following talks he had given to applied linguists, because he also draws from literary and cultural studies. 
Second language teaching and learning as a thematic focus in foreign language fields has changed shape over the past few decades in important ways, which have influenced the terms these scholars use to denote their research. Whereas Van Patten (1999) considered language teaching a subdiscipline under second language acquisition which he categorized as an area of applied linguistics, many contemporary scholars in second language teaching and learning - including almost all of my interviewees - do not identify with the term SLA. Their academic profiles list interests such as sociocultural approaches to language learning, literacy studies, multilingualism, discourse analysis, translation, second and foreign language pedagogy, educational linguistics, and curriculum development. Perhaps because their research interests and disciplinary repertoires have been shaped in programs in which both applied linguistics and literary studies are present, almost all of these scholars work in areas of literacy studies or L2 reading and writing. They are, as Emma jokingly identified herself, "text people." Given the more historicist and sociological bent of many literary studies scholars in contemporary foreign language departments, this creates an odd situation in which the applied linguists in some cases become the bearers of methodological traditions such as hermeneutics, narrative studies, genre theory, and stylistics, whose disciplinary histories are closely tethered to literary studies - and they help to keep these frameworks present in the field of applied linguistics.

\subsubsection{Transdisciplinarity on the career track}

It is unsurprising perhaps that the people in tenure-track positions who were not the sole applied linguists in their departments and who had opportunity to teach a range of courses including graduate seminars in special topics were the individuals who seemed overall most secure in their ability to conduct meaningful transdisciplinary work. In particular, Alice and Aaron did not perceive of transdisciplinarity having negatively impacted their bids for promotion and it is perhaps important to note that both were hired in as faculty specializing in literary and cultural studies and were located at research institutions. But even for those who occupy tenuretrack research positions, the translation of the transdisciplinary work of these scholars into recognizable research tracks within existing institutional structures often seemed to feel ad hoc and precarious. It is striking that, in this moment when tenure positions are becoming more scarce, two of the participants had or were in the process of willingly giving up tenure to take on more administrative positions that were more clearly delineated as foreign language education specialist - a position, in which they felt that their impact could be greater.

While it might at first seem counter-intuitive that scholars would sacrifice the security of tenure, which should in theory afford them more academic freedom, several comments from the participants suggested that at each level of promotion 
within academia, the potential for transdisciplinary work becomes more difficult. For example, Aaron commented that he had unwittingly discovered transdisciplinarity as an undergraduate and only in graduate school did this become more challenging. Iris felt that transdisciplinarity had been prized in her graduate program, but was difficult now that she had taken on her current position. Emma and Paul, both Associate Professors, expressed that they had been very happy with the tenure process at their institutions but that they had some concerns about what it would look like when they go up for Full Professor. With the U.S. academic system, promotion to Full Professor, more so than to Associate, is based on demonstrated contributions to their field, which means that there must be a shared agreement between the candidate, the institutionally-located promotion committee, and the external reviewers as to which field or fields are relevant. Chris also mentioned the particular pressures of research universities which prioritize specialization and make anyone who tries to work in more hybrid intellectual spaces seem like a bit of a "dilettante." Alice, the only very senior scholar whom I interviewed and seemingly the least bothered by matters of disciplinary identity, accounted for the success of inter- and transdisciplinary work at her university by saying: "My campus can promote people doing odd things." She felt that the emphasis at her university was less on whether someone fit a preconceived profile and more on what kinds of contribution a person was making.

Another recurring element in the narratives is important for understanding what processes of career advancement look like for these scholars. All of the individuals I interviewed had been asked to take on some kind of administrative role at their institutions. Although this ranged across the hierarchy of U.S. higher education - from Section Leader for a particular curriculum level to Language Program Director to Department Head to Dean - this is striking given that all but two of the participants were early or mid-career scholars and even those who were more advanced Associate Professors had been asked to take on these roles earlier in their career. In many of the interviews, it was explicitly mentioned that they had been asked because they were seen in their department or program as the "assessment person" or the "curriculum person." In this regard, they were recognized for and to an extent reduced to the potential institutional applications of their applied linguistics methodologies. Although a larger survey would be needed to verify if this is a larger trend, the experiences of the participants suggest that even where tenure-track positions exist for applied linguistics-literary studies border crosses, these scholars are more likely to be fast-tracked into administrative positions that decrease the time they can spend on research, which would reduce the number of advanced researchers with this kind of transdisciplinary profile. 


\section{Conclusion: Lessons from applied linguistics/literary studies go-beyonds}

Although the scholars I interviewed almost unanimously reported feeling some form of disjointedness in their professional identities, this seemed to relate almost exclusively to external perceptions and matters of tenure and promotion rather than any sense of intellectual or epistemic vertigo. The personal testimonies of the scholars interviewed in this study demonstrate that transdisciplinarity must be approached as something more than a form of intellectual enrichment. Institutional cultures and their role must be recognized or we risk relegating transdisciplinarity to the work of a relatively small number of privileged scholars. Because of their institutional homes, hierarchy as it relates to questions of hiring, tenure, and promotion was dominated most obviously by scholars in literature and culture and it is this power relationship that has received the most attention in publications reflecting on FLLC fields (as discussed earlier in this article), but there also seemed to be some lingering ambivalence towards applied linguistics among the scholars I interviewed. I myself have witnessed instances where scholars applying for a position that clearly emphasized applied linguistics or second language studies were interrogated about their ability to teach literature, but I have been involved in discussions of admissions, search, and promotion committees where the question has been raised as to whether someone is a "real applied linguist" or "applied linguistics enough" - in spite of leading voices from within that emphasize the fluidity of the field (Grabe, 2010). If we take for granted that applied linguistics is and has always already been transdisciplinary, we risk missing the everyday labors that go into maintaining the epistemological perspectives that truly crossdisciplinary work requires. We also sideline careful, critical investigations of our own assumptions of what constitutes rigor and prestige in the collective endeavors we recognize as applied linguistics and misrecognize that these systems of value are busy at work in the social mechanisms of academic systems.

If the institutional coupling of applied linguistics and literary studies in FLLC departments contributes to the intellectual development of scholars who are "text people," and who approach questions of meaning making with the theoretical and methodological offerings of the humanities in their repertoire, their presence in these departments offers not only literary studies a chance to look beyond itself in ways that many of the scholars I interviewed found appealing, but it also gives applied linguistics a chance to reflect on the potential limits of its transdisciplinarity. While these scholars almost all expressed frustrations and anxieties about the particular institutional hierarchies within which these discoveries had been born, they all described how the compulsion to mediate between academic discourses afforded them an ability to look beyond the scope of any given field. In particular, questions of poetics, aesthetics, and affect resurfaced again and again. 
Transdisciplinary approaches illuminate the spaces between and beyond disciplinary discourses, enable us to make use of disciplinary frames while simultaneously interrogating their limits (Byrd Clark, 2016). While applied linguistics should continue to celebrate its transdisciplinarity, it should not grow so certain of it that it loses the subversive elements of trans-perspectives. This means that in addition to defining what we accept as scholarly rigor and its boundaries, we might also find ways to embrace what Rosello (a comparative literature scholar) beautifully describes in his defense of rudimentariness as a productive epistemological position:

The choice that we make when we envisage theory as a (foreign) language or assume instead that each theorist is a speaker of our own language has consequences: if I treat theory as a language, I assume that it functions like the migrant's sometimes incomprehensible words. Some readers will be tempted to delegitimize that language in order to protect themselves from an unbearable feeling of incompetence and alienation. [...] If we treat theory as a foreign language, our responsibility is to learn the language.

(Rosello, 2011)

Rosello's depiction of transdisciplinarity as a form of translingualism (see also Liddicoat, this volume) affords further analogies between the work of transdisciplining and the kinds of multilingual scholarship the individuals whom I interviewed pursue. Although this did not come up explicitly in the interviews, the very reality of needing to mediate between applied linguistics and inexact translations such as Angewandte Linguistik and linguistique appliquée may have left them more open to feelings of incompetence and alienation and to the creative potential insights that can inure if one leans into feelings and makes them part of one's approach.

The situation of these scholars, whose transdisciplinary work is often first shaped not by methodological allegiances but by contextual pressures, creates a space in which applied linguistics can reflect on shared assumptions around how far out of familiar disciplinary frames of reference it is willing to go. To borrow Alice's formulation, what are we to do with "people who do odd things"? "People doing odd things" might not be a bad conceptual starting point for envisioning the transgressive aspects of transdisciplinary work, which risks being theorized away if "transdisciplinarity" is taken for granted as inherent to applied linguistics. If we accept that applied linguistics has always already been a transdiscipline, it is all the more important for us to notice when we get too cis-disciplinary. The boundaries of our methodological and theoretical frameworks and the range of disciplines they draw from must be continually rethought and expanded.

This brings me to the final point, transdisciplinarity requires active advocacy. This is especially the case because, as the conversion narratives from my interviews 
suggest, transdisciplinarity is often a process that emerges through professional encounters and is not something fledgling graduate students necessarily go out looking for. It would also be worthwhile, for example, to consider how professional organizations can acknowledge and expand the intellectual repertoires of especially but not exclusively early to mid-career researchers who wish to deepen their knowledge of research methods or paradigms. A model for this can be found in an organization like the Poetics and Linguistics Association, where each annual conference is preceded by a set of workshops designed to introduce scholars to new disciplinary methods (e.g. corpus linguistics, natural language processing, and rhetoric) and their potential use in the study of language and style. These events can also work as a form of advocacy by highlighting research paradigms that might otherwise fall outside of expected norms. By promoting transdisciplinarity, even radical transdisciplinarity, structurally as well as intellectually within and across spaces of power such as conferences and academic journals, we can ensure that the structures of hierarchization that scholars might face in their institutions are critically examined rather than reified within applied linguistics.

\section{Bibliography}

Allen, H. W. (2009). Beyond the language-literature divide: Advanced pedagogy for training graduate students. ADFL Bulletin, 41(2), 88-99. https://doi.org/10.1632/adfl.41.2.88

Allen, H. W., \& Paesani, K. (2010). Exploring the Feasibility of a Pedagogy of Multiliteracies in Introductory Foreign Language Courses. L2 Journal, 2(1), 119-142.

Berman, R. A. (1994). Global Thinking, Local Teaching: Departments, Curricula, and Culture. ADFL Bulletin, 7-11. https://doi.org/10.1632/adfl.26.1.7

Bernhardt, E. (2010). A reaction to the 2007 MLA Report. Reading in a Foreign Language, 22(1), $1-4$.

Butler, J. (2016). Rethinking Vulnerability and Resistance. In J. Butler, Z. Gambetti, and L. Sabsay (Eds.), Vulnerability in Resistance (pp. 12-27). Durham: Duke University Press.

https://doi.org/10.1215/9780822373490-002

Byrd Clark, J. (2016). Transdisciplinary Approaches to Language Learning and Teaching in Transnational Times Introduction to the Special Issue. L2 Journal, 8(4), 2-19.

Douglas Fir Group. (2016). A Transdisciplinary Framework for SLA in a Multilingual World. Modern Language Journal, 100, 19-47. https://doi.org/10.1111/modl.12301

Grabe, William. (2010). Applied linguistics: An emerging discipline for the twenty-first century. In R. B. Kaplan (Ed.), The Oxford handbook of applied linguistics (2 ed., pp. 3-12).

Gramling, D. (2016). Researching Multilingually in German Studies: A Brief Retrospective. German Studies Review, 39(3), 529-540. https://doi.org/10.1353/gsr.2016.0086

Halliday, M. A. K. (2001). New Ways of Meaning. In A. Fill \& P. Mühlhäusler (Eds.), The Ecolinguistics Reader. Language, ecology and environment (pp. 184-238). London: Continuum. Hiram, H., \& Maxim, H. H. (2004). Advanced Foreign Language Learning: A Challenge to College Programs. 
Katz, S., \& Watzinger-Tharp, J. (2005). Toward an Understanding of the Role of Applied Linguists in Foreign Language Departments. Modern Language Journal, 89(4), 490-502. https://doi.org/10.1111/j.1540-4781.2005.00326.x

Kern, R. (2000). Literacy and Language Teaching. Oxford: Oxford University Press.

Kramsch, C. (1993). Context and Culture in Language Teaching. Oxford: Oxford University Press.

Kramsch, C. (2011). The symbolic dimensions of the intercultural. Language Teaching, 44(1), 354-367. https://doi.org/10.1017/So261444810000431

Kramsch, C. (2015). Applied Linguistics: A Theory of the Practice. Applied Linguistics, 36(4), 454-465. https://doi.org/10.1093/applin/amv039

Kramsch, C. (2018). Trans-spatial Utopias. Applied Linguistics, 39(1), 108-115. https://doi.org/10.1093/applin/amx057

Kramsch, C., Howell, T., Warner, C., \& Wellmon, C. (2007). Framing Foreign Language Education In The United States: The Case Of German. Critical Inquiry in Language Studies, 4(2), 151-178. Retrieved from http://silk.library.umass.edu:2048/login?url=http://search. ebscohost.com.silk.library.umass.edu:2048/login.aspx?direct=true\&db=ufh\&AN=270228 56\&site $=$ ehost-live \&scope $=$ site

Maxim, H. H. (2006). Integrating textual thinking into the introductory college-level foreign language classroom. Modern Language Journal, 90(1), 19-32.

https://doi.org/10.1111/j.1540-4781.2006.00382.x

Maxim, H. H., Höyng, P., Lancaster, M., Schaumann, C., \& Aue, M. (2013). Overcoming Curricular Bifurcation: A Departmental Approach to Curriculum Reform. Die Unterrichtspraxis/ Teaching German, 46(1), 1-26. https://doi.org/10.1111/tger.10126

MLA. (2007). Foreign Languages and Higher Education: New Structures for a Changed World. Profession, 2007(1), 234-245. https://doi.org/10.1632/prof.2007.2007.1.234

Ortega, L. (2013). SLA for the 21st Century: Disciplinary Progress, Transdisciplinary Relevance, and the Bi/multilingual Turn. Language Learning, 63(1), 1-24.

https://doi.org/10.1111/j.1467-9922.2012.00735.X

Paesani, K., Allen, H. W., \& Dupuy, B. (2016). A Multiliteracies Framework for Collegiate Foreign Language Teaching. Upper Saddle River: Pearson.

Pennycook, A. (2018). Posthumanist Applied Linguistics. Applied Linguistics, 1-18. https://doi.org/10.1093/applin/amw016

Perrin, D. (2012). Transdisciplinary action research. Bringing together communication and media researchers and practitioners. Journal of Applied Journalism and Media Studies, 1(1), 3-23. https://doi.org/10.1386/ajms.1.1.3_1

Richardson, D. (2017). Beyond tolerance of ambiguity: Symbolic competence as creative uncertainty and doubt. L2 Journal, 9(2), 12-34.

Rosello, M. (2011). Rudimentariness as Home. In A. Behdad \& D. Thomas (Eds.), A Companion to Comparative Literature (pp. 312-331). Malden: Wiley-Blackwell. https://doi.org/10.1002/9781444342789.ch20

Russell, A. W. (2005). No academic borders?: Transdisciplinarity in university teaching and research. Australian Universities' Review, 48, 35-41.

Swaffar, J. (1999). The Case for Foreign Languages as a Discipline. ADFL Bulletin, 30(3), 6-12. https://doi.org/10.1632/adfl.30.3.6

Swaffar, J., Arens, K., \& Byrnes, H. (1991). Reading for Meaning: An Integrated Approach to Language Learning. Englewood Cliffs, NJ: Prentice Hall. 
van Lier, L. (2004). The Ecology and Semiotics of Language Learning: A Sociocultural Perspective. Utrecht: Kluwer Academic. https://doi.org/10.1007/1-4020-7912-5

Van Patten, B. (1999). What is second language acquisition and what is it doing in this department. ADFL Bulletin, 30(3), 49-53. https://doi.org/10.1632/adfl.30.3.49

Warner, C. (2011). Rethinking the Role of Language Study in Internationalizing Higher Education. Journal Issue: L2 Journal Journal, 3(3), 1-21. Retrieved from http://escholarship.org/uc/ item/7188g4z0\%0Ahttp://www.escholarship.org/help_copyright.html\#reuse\%0Ahttp:// repositories.cdlib.org/uccllt/12/vol3/iss1/art1/

Warner, C., \& Gramling, D. (2013). Gerade Dir hat er eine Botschaft gesendet Contact Pragmatics and the Teaching of Foreign Language Texts. In J. Plews \& B. Schmenk (Eds.), Traditions and transitions: Curricula for German studies (pp. 57-209). Waterloo: Wilfrid Laurier University Press.

Warner, C., \& Gramling, D. (2014). Kontaktpragmatik: fremdsprachliche Literatur und symbolische Beweglichkeit. Deutsch Als Fremdsprache, 50, 67-76.

\section{A. Protocol for semi-structured interviews}

1. First, can you tell me a little about your current position in your institution? Is there anything it might help me to know about your position?

2. In inviting you to participate in this study, I identified you as an applied linguist who also works in literary studies. I wanted to ask if you agree with that characterization? Would you add anything else to it?

3. Can you talk a little about your research? How did you become interested in these topics? In what ways did your educational background prepare you for the work you do? In what ways do you wish you were better prepared?

4. How do you understand the term transdiciplinarity as it relates to your work? To your institutional identity?

5. In what ways has transdisciplinary work between applied linguistics and literary studies been a benefit in your career? Are there also ways in which it has been disadvantageous? If yes, can you tell me about those?

6. Can you think of any particular moment or an event in which working transdisciplinarily significantly impacted how you were perceived by colleagues or peers? Can you tell me a little about this?

7. Is there anything else you think it would be helpful for me to know, as I work on this project? 


\section{B. Overview of participants}

\begin{tabular}{|c|c|c|c|c|}
\hline Pseudonym & $\begin{array}{l}\text { Status/Position at time } \\
\text { of interview }\end{array}$ & $\begin{array}{l}\text { Current Status/ } \\
\text { Position }\end{array}$ & $\begin{array}{l}\text { Primary } \\
\text { Language } \\
\text { Taught/ } \\
\text { Researched }\end{array}$ & $\begin{array}{l}\text { LPD } \\
\text { Experience? } \\
\text { ( = currently } \\
\text { serving) }\end{array}$ \\
\hline Aaron & Assistant Professor & Associate Professor & German & $\mathrm{N}$ \\
\hline Olivia & Assistant Professor & $\begin{array}{l}\text { Associate Professor } \\
\text { of the Practice }\end{array}$ & German & $\mathrm{Y} \bullet$ \\
\hline Emma & $\begin{array}{l}\text { Associate Professor / } \\
\text { Department Chair }\end{array}$ & - & German & $\mathrm{Y}$ \\
\hline Paul & Associate Professor & $\begin{array}{l}\text { Language } \\
\text { School/Center } \\
\text { Administrator }\end{array}$ & German & $\mathrm{Y}$ \\
\hline Iris & Lecturer in German & & German & $\mathrm{Y}$ \\
\hline Alice & Professor & & German & $\mathrm{N}$ \\
\hline Anne & $\begin{array}{l}\text { Associate Professor } \\
\text { / Language School/ } \\
\text { Center Administrator }\end{array}$ & - & French & $\mathrm{Y}$ \\
\hline Chris & $\begin{array}{l}\text { Associate Professor } \\
\text { / Language School/ } \\
\text { Center Administrator }\end{array}$ & - & French & $\mathrm{Y}$ \\
\hline Jeanne & Lecturer (retired) & - & French & $\mathrm{Y}$ \\
\hline Louise & Lecturer in French & - & French & $\mathrm{N}^{*}$ \\
\hline
\end{tabular}

*. Scheduled to take over this position in the next academic year. 